\title{
A experiência na formação social do sujeito e o interacionismo simbólico em G. H. Mead: contribuições para o Ensino de Filosofia no Ensino Médio ${ }^{1}$
}

\author{
The experience in the social formation of the subject and the symbolic \\ interacionismo in G. H. Mead: contributions for the Teaching of Philosophy in \\ the Secondary ${ }^{1}$
}

\section{José Gilliard Santos Silva}

Professor na Secretaria de Estado Educação e Cultura do Rio Grande do Norte e no Colégio Diocesano Seridoense, Caicó, Rio Grande do Norte, Brasil.

gilliardsantos2014@outlook.com - https://orcid.org/0000-0002-4370-6068

\section{Shirlene Santos Mafra Medeiros}

Professora doutora na Universidade do Estado do Rio Grande do Norte, Caicó, Rio Grande do Norte, Brasil.

shirlenemafra@yahoo.com.br - https://orcid.org/0000-0002-5594-8179

Recebido em 29 de junho de 2020

Aprovado em 11 de agosto de 2020

Publicado em 28 de outubro de 2020

\section{RESUMO}

O presente trabalho tem como objeto de estudo a análise dos conceitos de Interacionismo Simbólico de George Herbert Mead e Agir Comunicativo de Jürgen Habermas e suas contribuições para o ensino de Filosofia no Ensino Médio, articulada à uma ação educativa realizada no contexto da Escola Pública. A pesquisa consistiu em desenvolver uma metodologia de ensino de filosofia na escola pública, orientada numa perspectiva de identificação, problematização e busca por soluções de problemas com base em estudos da tradição filosófica e sua devida contextualização. A filosofia seria uma espécie de mediadora e guia, entre as diferentes formas de conhecimentos presente nas vidas dos estudantes, e teria o papel fundamental de organizar e articular criticamente, de acordo com seu contexto e necessidades, as diversas nuances dos saberes. A relevância da pesquisa, justifica-se, inicialmente, pelo fato de ser a primeira experiência prática de ensino, no Brasil, baseada no interacionismo simbólico de George Herbert Mead e suas contribuições para compreender a sociedade contemporânea; em segundo lugar, pela necessidade de se construir alternativas contra-hegemônicas de ensino, valorizando as experiências dos sujeitos, suas vivências diárias, buscando a constituição de uma ética e resolução de problemas.

Palavras-chave: Interacionismo Simbólico. Agir Comunicativo. Ensino de Filosofia.

\section{ABSTRACT}

The present work takes as a study object the analysis of the concepts of Interacionismo Simbólico of George Herbert Mead and to Act Communicatively of Jürgen Habermas and his contributions for the Philosophy teaching in the Secondary education, when an educative action carried out in the context of the Public school was articulated 
to. The inquiry consisted in developing a methodology of teaching of philosophy in the public school orientated in a perspective of identification, problematização and it looks for problems solutions on basis of studies of philosophical and his tradition for proper contextualização. The philosophy would be a mediator's sort and it drives, between the different forms of knowledges present in the lives of the students, and it would have the basic paper to organize and articulating critically, in accordance with his context and necessities, several nuances of to know. The relevance of the inquiry, it is justified, initially, because of being the first practical teaching experience, in Brazil, based on the symbolic interacionismo of George Herbert Mead and his contributions to understand the contemporary society; at as place, for the necessity of teaching alternatives - hegemônicas being built, valuing the experiences of the subjects, his daily existences, looking for the constitution of an ethics and problems resolution. Keywords: Symbolic Interacionismo. To act Communicatively. Teaching of Philosophy.

\section{Introdução}

Experiências desenvolvidas no âmbito do Ensino de Filosofia no Ensino Médio da rede pública, nos conduziram a refletir sobre a necessidade, possibilidade e viabilidade de experienciar vivências educativas orientadas pelas interações simbólicas, pelos processos de comunicação no interior da instituição escolar, em que se permita a formação social do sujeito crítico. reflexivo inserido nos processos de interações sociais.

Portanto, o presente trabalho, consiste na apresentação de uma síntese de uma pesquisa de mestrado desenvolvida e apresentada no Programa de Mestrado Profissional em Filosofia (PROF-FILO) da Universidade do Estado do Rio Grande do Norte, consistiu na elaboração e aplicação de uma metodologia de ensino-aprendizagem de filosofia no Ensino Médio, realizada na Escola Estadual Joaquim José de Medeiros, munícipio de Cruzeta, sertão do Rio Grande do Norte, numa turma de $1^{\text {a }}$ série do Ensino Médio, do turno matutino, com 25 estudantes, oriundos de diversos estratos sociais, com uma multiplicidade de experiências e visão de mundo, com duração de dois (02) meses.

O objetivo geral da pesquisa consistiu em analisar elementos epistemológicos e conceituais do pensamento filosófico de George Herbert Mead e Jürgen Habermas e suas contribuições para o ensino de Filosofia no Ensino Médio, bem como a construção de uma ação educativa, dialógica experienciada na Escola Pública.

O contexto cultural, econômico, político e social de nossa sociedade, na transição do século XX para o século XXI, juntamente com todas as suas transformações e problemáticas, que se fazem refletidas na organização da estrutura educacional de uma comunidade, coloca como ponto de partida a seguinte interrogação: Como desenvolver um novo modelo de sociabilidade que leve em consideração as individualidades e o diálogo? É nesse contexto que a filosofia de George Herbert Mead e seu diálogo com o pensamento de Jürgen Habermas aparecem como possibilidade de repensar a sociedade além de seus modelos normativos, tendo como horizonte um novo modo de organização, e um nova maneira de desenvolver os diversos tipos de relações, com base no diálogo, nas interações e na racionalidade, buscando, nos contextos das experiências individuais e sociais, desenvolver um olhar investigador e crítico de suas vivências.

Assim como o pensamento de Habermas pode nos orientar para entender a educação na sua dimensão interativa e no âmbito das experiências dos vários atores envolvidos 
nos processos formativos, Mead também, e podemos dizer com uma confiança maior que o próprio Habermas, acentua a importância das relações sociais, da comunicação (linguagem) e do emaranhando de laços culturais que os sujeitos estão envolvidos. Como podemos observar a colocação de Casagrande (2012, p. 117), "A educação consiste, na visão de Mead, num processo social, interativo e simbólico, por meio do qual os educandos respondem a uma situação organizada de aprendizagem". Nas entrelinhas do processo educacional meadiano, alguns elementos aparecem como elementares para a análise e compreensão de tal fenômeno. Como afirma Casagrande ${ }^{2}$ (2012), Mead evidencia três elementos acerca da educação: a dimensão social, a linguagem e o processo de formação dos significados e, correlativamente, da consciência de si mesmo.

Nesse sentido, a presente proposta de trabalho apresentou como objetivo construir uma proposta teórico-metodológica para o ensino de filosofia com base num processo interativo, que possibilitasse os sujeitos, mediante uma comunicação simbolicamente mediada, construir suas identidades num processo de formação interdependente. Dessa forma, seria possível construir valores, normas, conhecimentos, racionalmente validados, frutos de elaboração conjunta, participativa. Tal metodologia seria orientada numa perspectiva onde se observasse a identificação, problematização e busca por soluções de problemas com base em estudos da tradição filosófica e sua devida contextualização. Seguindo Habermas, no agir comunicativo, a socialização, a linguagem, além da função primordial de promover o entendimento, são responsáveis pela coordenação das atividades orientadas racionalmente, que envolve diferentes sujeitos, em diferentes etapas de interação. No entanto, encontra na Psicologia Social os fundamentos necessários para compreender e propor uma nova forma de agir de pensar, com um viés crítico e reflexivo, que possa conduzir o homem e a sociedade na direção de um mundo emancipado.

O trabalho está dividido em 03 (três) partes. A primeira parte apresentará Aspectos do pensamento de Habermas e de Mead e a consequente passagem do paradigma da consciência para o da comunicação intersubjetiva, bem como suas possíveis contribuições para pensar o ensino de Filosofia. A segunda parte ressalta o referencial teórico-metodológico, os instrumentos, a coleta de dados e método a ser utilizado na interpretação das informações coletadas. E a terceira parte corresponde a Ação Educativa desenvolvida na escola, no âmbito das aulas de Filosofia e, por fim, alguns resultados do trabalho de pesquisa.

\section{Habermas e Mead: aproximações entre Teoria Crítica e Interacionismo Simbólico e contrições para o Ensino de Filosofia}

Habermas é apontado como integrante de uma terceira geração dos pensadores da Escola de Frankfurt. Contudo, não se pode dizer que essa herança frankfurtiana é absoluta em todos os seus fundamentos e preceitos teóricos. Tanto pela abrangência de temas de sua obra, como pelos percursos metodológicos, pode-se afirmar que operou-se um distanciamento de pensamento entre Habermas e os primeiros pensadores de Frankfurt, mas existem. sem sombra de dúvidas, aproximações. Como afirma Rouanet (1987, p. 331), 
[...] existem em Habermas temas que no fundo são próximos dos grandes temas da teoria crítica (Escola de Frankfurt); a denúncia de um mundo crescente administrado, a preservação da ideia da utopia - a da comunicação ideal - e principalmente a fidelidade ao conceito iluminista de maioridade, Mündigkeit, como telos [Grifos do autor] da vida individual e coletiva. (ROUANET, 1987, p. 331)

Ao se deparar com a aporia em que caiu a crítica de Adorno à razão ocidental, Habermas percebe a necessidade de ampliar a compreensão e constituição de um modelo de racionalidade, a fim de oferecer uma possibilidade de reconstrução do aspecto crítico e emancipatório da razão. Nesse sentido, no entendimento de Rouanet (1987, p. 338), "Habermas tenta transcender esse pensamento paradoxal. Opondo ao conceito adorniano uma razão mais ampla, que não se baseie mais na relação sujeito-objeto e sim na relação entre sujeitos: a razão comunicativa." No processo de construção de ideia de uma racionalidade comunicativa, Habermas encontrará no pensamento de George Herbert Mead importantes contribuições para o que viria se tornar sua Teoria do Agir Comunicativo.

As contribuições meadianas em alguns aspectos do pensamento de Habermas, configura uma espécie de aproximação ou guinada da Teoria Crítica em relação as ideias centrais do Interacionismo Simbólico. Assim, é necessário observar, que tal aproximação seria impensável à luz do pensamento de Adorno, Horkheimer, Marcuse entre outros. Isso se configura pelo fato de pensadores apontarem uma relação estreita entre o pensamento filosófico norte-americano, traduzido na forma do Pragmatismo com as teses centrais do Positivismo. Como observa Mendonça,

Pragmatismo e teoria crítica são tradições frequentemente pensadas
como opostas no campo da ciência política. Tal visão é sustentada pelo
ceticismo da primeira geração de Frankfurt em relação à abordagem
norte-americana. O próprio Horkheimer associou o pragmatismo ao
positivismo, na medida em que ambas as perspectivas julgariam que
a "tarefa da ciência [era] a previsão e a utilidade dos resultados". A
aversão inicial dos frankfurtianos está vinculada a uma interpretação
do pragmatismo como conformista e pouco atento às relações de
poder. (MENDONÇA, 2013, p. 367 ).

É importante assinalar que Habermas, seguindo a crítica frankfurtiana (principalmente a empreendida por Adorno e Horkheimer) à racionalidade ocidental, entende esta como a capacidade de o homem agir e interagir no ambiente no qual ele está inserido. Nesse sentido a racionalidade não se resume apenas ao mero saber e o modo como acessá-lo, mas define-se a partir de sua estrutura argumentativa. Dessa forma, Habermas (1989, p. 321) entende o agir comunicativo como "[...] uma interação mediatizada simbolicamente. Ela se rege por normas que valem obrigatoriamente, que definem as expectativas de comportamento recíprocas e que precisam ser compreendidas e reconhecidas por, pelo menos, dois sujeitos agentes."

Assim, o pensamento habermasiano e, mais especificamente, sua Teoria do Agir Comunicativo tem como fundamento dois temas principais que devem de imediato serem superados: a filosofia do sujeito (da consciência) e seus resquícios metafísicos e a crítica 
a razão instrumental, que tem seus alicerces no conhecimento científico-tecnológico e que predomina hegemonicamente na moderna sociedade capitalista industrial. No Discurso Filosófico da Modernidade (2000), Habermas (p. 414) afirma que "[...] O que está esgotado é o paradigma da filosofia da consciência”. Esse esgotamento pode ser entendido pelo movimento feito pela razão nos últimos séculos, passando pelo lluminismo, até a atualidade. De uma razão totalizante, que englobava a natureza e a história, onde a vida dos indivíduos e as comunidades estavam inseridas, que continha os fins em si mesma, transformou-se numa razão calculista voltada para a probabilidade e para a estatísticas, e que perde a sua capacidade de autorreflexão. Como afirma Rouanet:

A razão objetiva, encarnada nas velhas tradições metafísicas e nas filosofias da modernidade emergente, permitia escolher fins em si mesmo razoáveis, enquanto a subjetiva designa a faculdade do espírito de mobilizar os meios mais adequados para atingir esses fins, sem que fossem suscetíveis de uma avaliação racional. (ROUANET, 1987, p. 332):

Em outras palavras, a razão, agora subjetiva ${ }^{3}$, grande herança do lluminismo, perde completamente sua capacidade de pensar fins e valores, transformando-se em mera empiria, colocando-se a serviço do capital e do progresso tecnológico.

Como alternativa para a superação da filosofia do sujeito e do modelo de racionalidade instrumental, predominante na sociedade contemporânea, Habermas propõe um modelo de razão comunicativa, que substituía a relação sujeito-objeto - própria da filosofia da consciência - pela relação do sujeito com outros sujeitos, mediada pela linguagem e pela interação. Nesse sentido afirma Habermas (2000, p. 413) "[...] Sugeri naquelas passagens (nas lições sobre o Discurso Filosófico da Modernidade) que o paradigma do conhecimento de objetos deveria ser substituído pelo paradigma do entendimento entre sujeitos capazes de falar e agir". Nesse modelo de racionalidade comunicativa proposto por Habermas, os indivíduos são pensados em condição de igualdade e dentro do processo de interação, que mediante a troca de conhecimentos, construíram as bases, não apenas do conhecimento e da sociedade, mas da própria personalidade, tendo em vista que no processo comunicativo existe uma troca reciproca de informações e de valores. Dessa forma Habermas (2000, p.414) afirma "[...] no paradigma do entendimento recíproco é fundamental a atitude performativa dos participantes da interação que coordenam seus planos de ação ao se entenderem entre si sobre algo no mundo".

O caminho escolhido por Habermas para construir sua Teoria do Agir Comunicativo foi o da interação entre os sujeitos mediante a linguagem, e para ser mais específico, tomou como base para sua construção teórica o Interacionismo Simbólico de George Herbet Mead. Nesse sentido, afirma Habermas (2012, p. 07): "Por isso, se alguém pretende liberar a força revolucionária inerente às categorias fundamentais da teoria do comportamento e utilizar seu potencial para implodir paradigmas, é forçado a retomar à Psicologia Social de G. H. Mead 4 ." Habermas tenta encontrar na Psicologia Social de Mead, os fundamentos 
para o funcionamento de sociedades complexas, como a contemporânea, como sendo o resultado de um agir cooperativo, ou seja, todo o nosso complexo de relações e de produção de conhecimentos e significados, tem origem numa situação de interações simbolicamente mediadas. Como afirma Radl Philipp (1996, p. 138), filósofa alemã - e orientanda de Habermas -, "todo o sistema teórico conceitual da Teoria do Agir Comunicativo de Habermas está baseado nos fundamentos do Interacionismo Simbólico de G. H. Mead."

Ao partir da ideia de que todas as relações humanas são sociais e que, categorias como razão, conhecimento, mente e consciência se constituem a partir dessas relações, Mead identifica a Linguagem como elemento que permite essa constituição intersubjetiva dos sujeitos e da sociedade. Sobre a importância da linguagem nos processos interativos, Mead (2010, p. 80) destaca que "A importância crítica da linguagem no desenvolvimento da experiência humana reside no fato de que o estímulo é de tal natureza que pode interferir na pessoa que fala da mesma maneira como interfere no outro."

Essa atitude de nos vermos como os outros nos veem, e vice-versa, torna-se o ponto de partida para a construção de linguagem de símbolos, que por sua vez, será o elemento central na construção de sentidos e significados, construídos numa dimensão intersubjetiva. Nota-se que para Mead, a ideia de uma consciência individual, ao molde cartesiano, sem relação nenhuma com o contexto social e com as experiências dos sujeitos, não tem nenhum sentido. Essa construção de sentidos e significados coletivos, numa matriz intersubjetiva, possibilita o surgimento daquilo que Mead chama de "comunicação consciente."

O caminho do Interacionismo Simbólico, escolhido por Habermas, para fundamentar seu Agir Comunicativo, não consiste num emaranhado de conceitos filosóficos e linguísticos. Pelo contrário, a escolha pela análise das relações e inter-relações, está diretamente ligada a seu percurso de vida,

A experiência cirúrgica fê-lo experimentar a dependência em relação aos outros. Nesse particular, mais tarde, segundo ele, a natureza social da humanidade se tornou tema de reflexão, passando a conceber o homem, a partir de Aristóteles, como um animal que vive num espaço público. (DUTRA, 2009, p. 305)

A importância que Habermas concebe ao processo de construção das relações interpessoais, das normas dos valores morais e sociais e a necessidade de compreender esse processo é bastante evidente. O que é negligenciado, na maioria das vezes, é a força que a ideia de intersubjetividade, própria do pensamento G. H Mead, faz-se presente no pensamento habermasiano. O próprio Habermas, deixa claro em várias situações, a relevância do pensamento meadano para sua produção teórica. Nessa linha de raciocínio afirma Habermas (2012, p. 45), "[...] Mead se interessa pela construção complementar do mundo subjetivo e do mundo social, como também pela gênese do si mesmo e da sociedade, a partir do contexto de uma interação mediada pela linguagem e regida por normas".

Portanto, tentar pensar a educação em Mead $^{5}$ e em Habermas ${ }^{6}$ é pensar a ação educativa como uma ação essencialmente social. E que o ambiente escolar deve ser 
compreendido a partir do contexto das experiências sociais, históricas, econômicas e políticas dos diversos atores que fazem o espaço escolar. Tal contexto deve ser orientado pela prática do diálogo e das relações interativas entre os sujeitos que constituem a comunidade educativa.

\section{Aportes teórico-metodológicos da pesquisa}

Como já foi salientado, o presente texto é resultado de uma tentativa de sintetizar uma pesquisa de mestrado desenvolvida e apresentada no Programa de Mestrado Profissional em Filosofia (PROF-FILO) da Universidade do Estado do Rio Grande do Norte. A pesquisa foi desenvolvida em dois momentos: o primeiro que corresponde aos fundamentos teórico-metodológicos, foi orientado pela análise dos conceitos de interacionismo simbólico, formação social do sujeito, agir comunicativo e ensino de filosofia, com base no pensamento de George Herbert Mead e Jürgen Habermas. O segundo momento, se refere ao desenvolvimento de uma proposta de ação educativa que consistiu na elaboração e aplicação de uma metodologia de ensino-aprendizagem de filosofia para o Ensino Médio. O trabalho foi norteado pela construção e participação coletiva dos envolvidos (estudantes e professor), onde as experiências individuais, os diversos valores, o contexto social, os significados construídos e reconstruídos pelos atores envolvidos no processo, foram levados em consideração para a fundamentação do referido trabalho.

Do ponto de vista metodológico, optou-se pela abordagem do Interacionismo Simbólico, que como afirma Uwe Flick (2009, p. 68) "trata do estudo dos significados subjetivos e da construção individual de significado." Dessa forma, todo o trabalho da pesquisa foi orientado pelo modo como os sujeitos constroem significados para suas experiências e ações de acordo com o contexto no qual está inserido, ou como assevera Flick (2009, p. 69) "O ponto de partida empírico [do Interacionismo Simbólico] consiste no significado subjetivo atribuído pelos indivíduos a suas atividades e ambientes." A abordagem metodológica do Interacionismo Simbólico privilegia as interações entre os sujeitos e os significados construídos a partir da reciprocidade dessas relações interativas.

Ao escolher o Interacionismo Simbólico como abordagem metodológica para fundamentar a referida pesquisa de mestrado (aspectos teóricos e práticos), optou-se por uma abordagem que reconheça o papel central das relações intersubjetivas entre os sujeitos que compõem uma determinada comunidade, e que privilegia as interações sociais como o ambiente onde se constrói coletivamente os significados, as normas, os valores que norteiam uma sociedade e seus atores. No caso específico da parte prática da pesquisa -, que teve uma sala de aula ( $1^{a}$ série) do Ensino Médio público como campo empírico-, é possível identificar uma grande diversidade de experiências, de expectativas, de saberes. E que, mesmo diante da diversidade e complexidade de opiniões e valores, existe uma determinação recíproca na construção e validação desses saberes.

Como procedimento metodológico da pesquisa, foi adotado o modelo de observação participante, debates e discussões com estudantes, na construção coletiva da metodologia de ensino-aprendizagem de filosofia. Como afirma Gil 
A observação participante ou observação ativa, consiste na participação real do conhecimento na vida da comunidade, do grupo ou de uma situação determinada. Neste caso, o observador assume, pelo menos até certo ponto, o papel de um membro do grupo. Daí que se pode definir observação participante como a técnica pela qual se chega ao conhecimento da vida de um grupo a partir dele mesmo.

(GIL, 1999, p. 113)

A coleta de dados foi orientada por entrevistas semipadronizadas ou semiestruturadas, e questionários abertos aplicados aos estudantes envolvidos na pesquisa. No tocante a entrevista semipadronizada, Flick (2009, p.149) relata que essa abordagem foi desenvolvida por Brigitte e Scheele, ao longo das décadas de 1980 e 1990, para estudar teorias subjetivas em campos como escolas e outras áreas de trabalho profissional. Ainda segundo Flick (2009, p.149), "o termo teoria subjetiva" refere-se ao fato de os entrevistados possuírem uma reserva complexa de conhecimento sobre o tópico em estudo."

Os dados resultantes da utilização desses procedimentos foram registrados na forma de anotações (diário de campo) e com o uso de gravação de áudio ou vídeo. A necessidade desses registros é defendida por Gil (1999, p. 125-126) ao afirmar que, "o único modo de reproduzir com precisão as respostas é registrá-las durante a entrevista, mediante anotações ou com o uso de gravador." O diário de campo, como ferramenta de registro de experiências e de dados coletados durante o percurso da pesquisa é tido como essencial para Minayo (1994, p. 63-64), ao enfatizar que "O diário de campo é pessoal e intransferível. Sobre ele o pesquisador se debruça no intuito de construir detalhes que no seu somatório vai congregar os diferentes momentos da pesquisa."

A metodologia de análise dos dados coletados durante a pesquisa, se deu pelo viés interpretativo das informações construídas e registradas. De acordo com Lakatos e Marconi (2007, p.169) "Uma vez manipulados os dados e obtidos os resultados, o passo seguinte é a análise e a interpretação dos mesmos, constituindo-se ambas no núcleo central da pesquisa."

\section{Ação educativa: desigualdade e violência nos diferentes espaços}

Pensar uma proposta de ação educativa que leve em consideração as experiências individuais e socais dos atores envolvidos (estudantes, professor, a escola como um todo, as famílias, o contexto exterior à escola) configura-se como um grande desafio na sociedade atual. As dificuldades são de várias ordens. Uma primeira dificuldade encontra-se na estrutura estatal engessada que organiza e controla os processos educacionais. Tais processos, na maioria das vezes, são verticais, hierarquizados e unilaterais, fazendo com que os programas e propostas pedagógicas sejam lançados de forma impositiva, não respeitando as diversidades e complexidades existente num país continental, como é o caso do Brasil. Um segundo problema consiste no fato que tais processos educacionais sejam orientados, quase que exclusivamente, por uma lógica mercadológica e instrumental, que é marca da sociedade contemporânea, resultando daí, uma adequação quase que absoluta à interesses econômicos. O argumento de que a educação deve voltar-se para formar e qualificar os sujeitos para o mercado de trabalho torna-se quase que absoluto e incontestável. Ocorre que 
o problema não está na formação para o exercício do trabalho (que sem dúvida é importante), mas que, nas entrelinhas dos modelos de educação tecnicista, está o esvaziamento da dimensão crítica e emancipatória dos sujeitos, representados na forma da especialização de saberes, valorização de conhecimentos técnico-científicos em detrimentos dos conhecimentos sociológicos, filosóficos e estéticos.

Como consequência lógica desse contexto de engessamento institucional da organização educacional, observa-se a elaboração de propostas pedagógicas voltadas para a formação técnico-profissional, desprezando, contudo, as especificidades dos sujeitos envolvidos, suas perspectivas e sua própria autonomia. Como afirma Dalbosco,

Processos pedagógicos relacionam-se com a formação de individualidades autônomas. Neles descortinam-se, amplamente, o conteúdo e as dificuldades da dimensão formativo-educacional do ser humano. Buscar seu espaço, ser alguém com dignidade e reconhecimento social são desejos de todo ser humano sensato. Essa busca está conectada a processos de aprendizagem e, por isso, questões sobre o que forma e educa o ser humano e o como ele se educa e se forma em sua relação com os outros, com as instituições e com o meio ambiente são decisivas para a pedagogia e a filosofia. (DALBOSCO, 2010, p. 27)

A proposta educativa desenvolvida foi orientada na perspectiva de valorizar a formação voltada para autonomia dos sujeitos, possibilitando um olhar crítico da realidade à sua volta e que possibilite construir uma postura emancipatória diante do contexto social, econômico, político e ideológico no qual possa estar inserido. Com base nos conceitos de Interacionismo Simbólico de Mead, agir comunicativo de Habermas e Ação educativa emancipatória e crítica de Radl Philipp, todo o trabalho foi construído coletivamente com os estudantes, professor, com a comunidade escolar e com participação sujeitos da localidade, principalmente ex-alunos que realizaram oficinas de teatro e de uso de aplicativos e tecnologias de comunicação. Como defende Radl Philipp,

[...] la meta educativa de la emancipación no puede ser definida e impuesta unilateralmente por parte de la persona o instancia educadora -extremo que negaría la condición de sujeto al educando-, la misma meta ha de anticiparse ya como condición estructural del propio proceso educativo en las situaciones educativas singulares concibiendo a éstas caracterizadas por una relación entre sujetos. (RADL PHILIPP, 2014, p. 158).

O ponto de partida para a construção da ação educativa "DESIGUALDADE E VIOLÊNCIA NOS DIFERENTES ESPAÇOS" se deu a partir da escolha dos sujeitos da pesquisa para o desenvolvimento e planejamento para a execução da atividade. Escolheu-se, assim, uma turma de $1^{\text {a }}$ série do Ensino Médio, do turno matutino, com 25 estudantes, oriundos de diversos estratos sociais, com uma multiplicidade de experiências e visão de mundo. O plano de trabalho para a construção da metodologia do Interacionismo Simbólico e Agir Comunicativo 
para o ensino de filosofia foi elaborado para se desenvolvido durante um bimestre letivo inteiro. Na escola pública, um bimestre contempla 10 aulas de filosofia, visto que o currículo nacional e estadual prevê uma aula por semana. Essas 10 aulas estão subdivididas em 6 momentos: 1) Apresentação, fundamentação epistemológica e discussão de algumas ideias centrais de Mead e Habermas (02 aulas); 2) Orientações sobre a metodologia e construção coletiva da temática a ser trabalhada (01 aula); 3) Pesquisa, fundamentação epistemológica e discussão das temáticas escolhidas (02 aulas); 4) Elaboração de curta-metragem como forma de avaliação (03 aulas); 5) apresentação dos curtas-metragens para a comunidade escolar (01 aula); e 6) avaliação coletiva do trabalho (01 aula).

O primeiro momento do trabalho consistiu na apresentação dos autores que norteou todo o trabalho da pesquisa de mestrado e ofereceu os pressupostos teórico-metodológicos para a construção de uma metodologia de ensino de Filosofia. Nesse sentido, no contexto das discussões que permeiam as aulas de filosofia, foi apresentado aos estudantes a possiblidade de desenvolver esse trabalho experimental. Em seguida, foi feito um trabalho de fundamentação epistemológica com estudantes, apresentando algumas ideias centrais de Mead e Habermas, tais como interacionismo simbólico, interação social, Self, agir comunicativo, diálogo, comunidade ideal de fala, etc. Além de pesquisa biográfica dos autores, foram trabalhadas partes específicas de textos e discutidas em rodas de conversas.

Uma metodologia de ensino que seja orientada pelo Interacionismo Simbólico e Agir Comunicativo deve privilegiar as interações sociais, as experiências individuais, o diálogo e as expectativas e anseios dos atores envolvidos na ação educativa. Dessa forma, o segundo momento, no desenvolvimento da metodologia, foi debater e escolher coletivamente uma temática a ser estudada nas aulas de filosofia. Nesse sentido, foi feita uma discussão em que cada estudante apresentasse sua proposta temática e seus argumentos e que, ao final do debate, fosse escolhido consensualmente um objeto de estudo. Ao final das discussões, foram escolhidas duas temáticas: a desigualdade social e a violência. Ao privilegiar o discurso e as interações sociais e a experiência dos sujeitos, o método do Interacionismo Simbólico sugere que, na visão de Polli,

O intento é levar um entendimento intersubjetivo, considerando o que cada participante do processo comunicativo pensa e argumenta sobre as questões em debate, para que todos os participantes possam posicionar-se e, como possibilidade, convergir em consensos prováveis e provisórios. (POLLI, 2013, p. 17)

Trazendo esses temas para o âmbito da investigação filosófica, foram sugeridos, com a mediação do professor, alguns pensadores para fundamentar epistemologicamente as pesquisas e debates. Ao final, foram construídos dois eixos conceituais que nortearam as aulas e os trabalhos: $A$ banalização do mal e o pensamento de Hannah Arendt e A origem das desigualdades sociais no pensamento de Rousseau.

Escolhidos os temas e autores, os estudantes foram orientados a fazer pesquisas e leituras das obras dos autores, sempre buscando fazer a articulação com os objetos de estudos 
definidos, o que constituiu o terceiro momento do trabalho. Além de pesquisas na internet e artigos científicos, foram estudados partes (fragmentos) de texto de Rousseau, Discurso sobre a origem e Os fundamentos da desigualdade entre os homens, e como também do texto Sobre a violência de Hannah Arendt. Como forma de socializar as pesquisas, foi feita uma discussão coletiva dos resultados e dos pontos que poderiam ser relacionados com a realidade dos próprios discentes. Sobre a importância de momento de discussão, Polli (2013, p. 17) defende que "a finalidade do debate intersubjetivo é coordenar ações de maneira cooperativa, tendo como fim a formação de uma opinião que possa levar a um comportamento social solidário e cooperativo."

É importante observar que esse trabalho contou com uma carga horária mínima na escola, mas sua maior parte foi realizada nos momentos de estudos fora do horário de aula na instituição.

Em continuação das atividades, decidiu-se coletivamente elaborar dois curtasmetragens, tendo como referência as duas temáticas pesquisadas e debatidas em sala de aula. Este constituiu o quarto momento da construção da metodologia de ensino de filosofia. A turma foi dividida em dois grupos: um grupo iria produzir um curta-metragem sobre a violência e o outro grupo sobre a desigualdade social. A escolha da referida atividade levou em consideração o nível de interação social, ações coletivas e diálogo para ser realizada, o que está diretamente ligado as premissas do Interacionismo Simbólico e Agir Comunicativo. Um elemento importante de ser destacado nessa etapa do trabalho foi a ação desenvolvida junto com a responsável pela biblioteca da escola, a professora, que organizou três oficinas para orientar a produção dos curtas-metragens. A primeira oficina foi de orientação para pesquisa em bibliotecas e na internet; a segunda, em parceria com um produtor de cinema local, teve como objetivo orientar a construção de roteiros cinematográficos; a terceira oficina, também contado com o apoio de pessoas fora da comunidade escolar, teve como objetivo, mostrar aos estudantes que tipos de tecnologias são necessárias para a gravação de um filme e como devem ser utilizadas. A referida oficina foi desenvolvida por um ser ex-estudante da escola, que trabalha no mercado de mídias digitais. Portanto, é possível observar que a metodologia que foi construída, sempre levou em consideração as expectativas dos estudantes, suas experiências sociais e individuais, bem como a interação, não apenas entre os estudantes, mas com diversos atores importantes que promovem o fazer educativo, sejam aqueles que pertencem a instituição escolar, sejam aqueles que estão fora da estrutura educacional formal, mas que podem contribuir de forma significativa, colocando o diálogo aberto e livre como elemento mediador do processo educativo. Dessa maneira, afirma Polli (2013, p. 20), "a aprendizagem se dá a partir da capacidade de interação proporcionada pela prática discursiva, numa motivação em torno da busca de uma verdade consensual em forma cooperativa."

Com o desenvolvimento do trabalho nas oficinas, deu-se seguimento às atividades que foram planejadas e partiram para a produção propriamente dita dos curtas-metragens. Os momentos de estudos, pesquisas e debates encontraram seu ápice na elaboração dos pequenos filmes. O trabalho coletivo, as interações, o diálogo e as experiências 
individuais e sociais constituem elementos importantes nesse tipo de atividades. Cada grupo fez a apresentação do seu curta-metragem e sua respectiva temática para a comunidade escolar, explicando os temas, motivações, dificuldades e aprendizagens. Dessa forma, ao compartilhar as experiências do trabalho desenvolvido com a comunidade escolar, os sujeitos envolvidos na ação educativa, buscam por meio do discurso, motivar os demais a reconhecerem o valor e a importância do trabalho, bem como despertar o interesse por conhecer e participar desse tipo de ação. O percurso da metodologia do Interacionismo Simbólico e Agir Comunicativo alcança, assim, seu quinto momento.

Com base na perspectiva do agir comunicativo e das experiências individual e social construídas pelos sujeitos ao longo desse percurso, o sexto e último passo foi voltado para uma avaliação coletiva, a partir de uma roda de conversa, onde todos tiveram a oportunidade de usar da palavra livremente, para analisar todo o percurso do trabalho, os pontos positivos e negativos, o que poderia ser melhorado, os principais obstáculos e suas impressões sobre a metodologia desenvolvida, buscando o entendimento e o consenso daqueles que compõem o grupo ou comunidade.

\section{Considerações finais}

As pesquisas desenvolvidas sobre Interacionismo Simbólico, da formação social do sujeito no pensamento filosófico de George Herbert Mead, o diálogo com algumas ideias de Habermas, mais especificamente o seu Agir Comunicativo, possibilitaram uma compreensão dos processos de interação social e de uma linguagem simbolicamente mediada, na constituição da identidade dos sujeitos e da própria sociedade. Nesse sentido, os sujeitos devem ser percebidos na lógica de suas experiências culturais e no contexto das relações com outros sujeitos. Dessa forma, percebe-se que as ideias meadianas para análise da sociedade contemporânea e de suas estruturas, com base nos processos de interações sociais e intersubjetivas, podem oferecer significativas contribuições para educação, bem como para o ensino de filosofia. Importante de ser ressaltado é o uso do termo metodologia, no contexto do trabalho, principalmente quando está relacionado com os modos de trabalhar as aulas de filosofia, e que, vale enfatizar, não deve ser tomado como um caminho fechado, dotado de regras e pressupostos a serem seguidos. Tal interpretação seria incompatível com o pensamento meadiano e habermasiano. O termo metodologia, refere-se mais a delineamentos e ações que precisam ser levadas em consideração, como as interações sociais dos atores que fazem o processo educacional, seu contexto sociocultural, suas experiências e saberes do cotidiano e sua devida articulação com o saber filosófico, na solução de problemas.

Tal metodologia possibilitou aos sujeitos que fazem a comunidade escolar, principalmente aos estudantes, a oportunidade de participarem como protagonistas dessa construção, e não apenas meros receptáculos de propostas pedagógicas desprovidas de significados e relações com suas vidas e visão de mundo. Portanto, o fato de que a pesquisa que desenvolvemos na escola proporcionou um caminho diferente dos que estão previstos nas cartilhas governamentais, já faz da referida metodologia, uma proposta 
contra-hegemônica de ensino e de escola. Dessa forma, podemos apontar alguns resultados de nossa pesquisa:

1 - A partir dos estudos de elementos da filosofia de Mead (Interacionismo Simbólico) e do pensamento de Habermas (mais especificamente elementos do Agir Comunicativo), é possível e viável fazer uma articulação prática entre a formação social do sujeito para inserir na práxis educativa institucional e no Ensino de Filosofia. Privilegiando as interações sociais, as experiências individuais e coletivas e a comunicação como mediadora desse processo. Os dados da pesquisa apontam que a referida articulação possibilita que ações educativas sejam desenvolvidas levando em consideração as experiências dos sujeitos envolvidos, trazendo a reflexão filosófica para o contexto de sua realidade individual e social. Desse modo, o estudante será capaz de articular o saber filosófico com temáticas que fazem parte de seu cotidiano e que, tendo acesso aos saberes da filosofia, é possível analisar e compreender tais temáticas a partir de diversos ângulos e perspectivas, aproximando-se daquela que melhor fizer sentido e significado para suas vidas.

2 - É possível desenvolver uma metodologia de ensino de filosofia fundamentada nas concepções meadianas do Interacionismo Simbólico e noAgir Comunicativo habermasiano, com vistas a resolução de problemas e desenvolver uma reflexividade crítica e emancipatória de sua própria realidade. Nesse sentido, ficou perceptível na observação feitas pelos estudantes nos questionários e nas entrevistas que o objetivo principal da metodologia trabalhada consistiu em promover uma análise reflexiva sobre os diversos problemas que estão presente na realidade das pessoas, em nosso caso, dos sujeitos que fazem a escola pública, e que essa reflexividade possibilite uma tomada de atitude frente a esses problemas com vistas a superação. Ao defender a construção de uma postura crítica e emancipatória por parte dos estudantes, o que se propõe é que esses sujeitos assumam o controle de suas vidas e ações e que possam colocar sua realidade como problemática filosófica, seja qual for o conflito ou situação.

3 - Tomando como referência a discussão teórico-metodológica desenvolvida ao longo do presente texto, podemos afirmar que o conceito de Interacionismo Simbólico de George Herbert Mead é uma perspectiva filosófica, haja vista que consiste numa tentativa de compreender o indivíduo contemporâneo e a realidade plural na qual está inserido no âmbito das interações sociais, da linguagem e das experiências. Constituindo, portanto, uma proposta teórico-metodológica pós-metafísica.

Em suma, todo o trabalho desenvolvido e apresentado, enfatiza a necessidade de se fazer o ensino de filosofia a partir de uma articulação direta com as experiências individual e social dos estudantes e, que seja valorizado os diversos níveis de interação, que o diálogo seja o elemento central nesse processo de construção coletiva de aulas de filosofia. Portanto, se torna urgente romper com as metodologias unilaterais e impositivas, seja nas aulas de filosofia ou em qualquer outro componente curricular. É o grande desafio das metodologias de ensino em nosso tempo. Nesse sentido, os estudos do Interacionismo Simbólico e do Agir Comunicativo podem oferecer fundamentos teóricos e metodológicos importantes para (re)construção dos processos educacionais. 


\section{Referências}

ARENDT, Hannah. Sobre a violência; Tradução André de Macedo Duarte. Rio de Janeiro: Civilização brasileira. 2009.

BANNELL, Ralph Ings. Habermas \& a Educação. Belo Horizonte: Autêntica Editora, 2006.

CASAGRANDE, C. A. A formação do eu em Mead e Habermas: desafios e implicações à educação. Tese (doutorado) - Pontifícia Universidade Católica do Rio Grande do Sul Programa de Pós-Graduação em Educação. - Porto Alegre, 2012.

DALBOSCO, Cláudio Almir. Pragmatismo, teoria crítica e educação: ação pedagógica como mediação de significados. Campinas, SP: Autores Associados, 2010. 260p.

FLICK, Uwe. Introdução à pesquisa qualitativa. Tradução Joice Elias Costa. - 3. Ed. Porto Alegre: Artmed, 2009.

GIL, Antônio Carlos. Métodos e técnicas de pesquisa social. 5. Ed. - São Paulo: Atlas, 1999.

HABERMAS, Jürgen. Teoria do Agir Comunicativo. (I) Racionalidade da ação e racionalidade social. Tradução de Paulo Astor Soethe. - São Paulo: Editora WMF Martins Fontes, 2012.

HABERMAS, Jürgen. Teoria do Agir Comunicativo. (II) Sobre a crítica razão funcionalista. Tradução de Flavio Beno Siebeneichler. - São Paulo: Editora WMF Martins Fontes, 2012.

HABERMAS, Jürgen. O Discurso Filosófico da Modernidade: doze lições. Tradução de Luiz Sérgio Repa, Rodnei Nascimento. - São Paulo: Martins Fontes, 2000. (Coleção Tópicos).

HABERMAS, Jürgen. Consciência moral e agir comunicativo. Tradução Guido Antônio A. de Almeida. - Rio de Janeiro: Tempo Brasileiro, 1989.

HORKHEIMER, M. Eclipse da razão. Trad. Sebastião Uchoa Leite. São Paulo: Centauro, 2002.

MARCONI, M. de A.; LAKATOS, E. M. Fundamentos de metodologia científica. 6. ed. São Paulo: Atlas, 2007.

MEAD, G. H. Mente, Self e Sociedade. (org). Charles W. Morris. São Paulo: Ideias e Letras, 2010.

MENDONÇA, Ricardo Fabrino. Teorias Críticas e Pragmatismo: a contribuição de G. H. Mead para as renovações da Escola de Frankfurt. In: Revista Lua Nova. Nº 90. 2013.

MENEZES, Anderson de Alencar. A teoria do agir comunicativo e os processos de aprendizagem. In: PERSPECTIVA FILOSÓFICA - Revista dos Programas de Pós-graduação em Filosofia da Universidade Federal de Pernambuco e da Universidade Federal da Paraíba. (Org.) Junot Cornélio Matos. Volume II - No 38 (agosto a dezembro de 2012).

MINAYO, Maria Cecília de Souza (Org.) Pesquisa Social: teoria, método e criatividade. Petrópolis, RJ: Vozes, 1994.

POLLI, José Renato. Habermas: agir comunicativo e ética do discurso. - Jundiaí, SP: Editora in House, 2013. 
RADL PHILIPP, Rita Maria. Sociologia Crítica: Perspectivas Actuales. Madrid - Espanha: Editorial Síntesis, 1996.

RADL PHILIPP, Rita Maria. Teoria hermenêutica-crítica frankfurtiana: interés espistemológico emancipativo y práticas de pedagogía crítica. In: Revista Binacional Brasil Argentina. - Vitória da Conquista.v 03. No 02.pag. 146-174. Dezembro/2014.

\title{
ROUSSEAU, Jean-Jacques. Discurso sobre a origem e os fundamentos das desigualdades entre os homens. São Paulo: Nova Cultura. 1991.
}

\author{
ROUANET, Sérgio Paulo. As razões do iluminismo. São Paulo: Companhia das Letras, \\ 1987
}

\section{Notas}

$1 \mathrm{O}$ presente texto representa tentativa síntese de um trabalho de dissertação de Mestrado, apresentado ao Programa de Mestrado Profissional em Filosofia - PROF/FILO da Universidade do Estado do Rio Grande do Norte -UERN, sob orientação da Dra. Shirlene Santos Mafra Medeiros, e apresentado no VI Encontro do GT Filosofar e Ensinar a Filosofar, realizado na Universidade Federal do Maranhão, entre 15 e 17 de outubro de 2019.

2 Ver: Casagrande (2012): Mead dá destaque especial a três elementos, que, sincronizados e conjuntamente, conformam um olhar diferenciado acerca da educação: a importância da dimensão social e da organização da vida da comunidade, com seus valores, ritos de iniciação e de transmissão dos conteúdos culturais, nos processos formativos; a linguagem, enquanto interação social e campo de produção e de reprodução de significados e conceitos; e o processo de formação dos significados e, correlativamente, da consciência de si mesmo. (CASAGRANDE ,2012, p. 117). A aula 38, do curso de 'Filosofia da Educação', apresenta uma retomada e uma síntese desses três elementos citados (Cf. MEAD, 2008).

${ }^{3}$ Essa distinção entre razão objetiva e subjetiva segue a argumentação de Horkheimer presente na obra Eclipe da Razão. Para Horkheimer (2002, pag. 11), o que define esse tipo de racionalidade é que esta seria "[...] uma faculdade subjetiva da mente. [...] Em última instância, a razão subjetiva se revela como a capacidade de calcular probabilidades e desse modo coordenar os meios corretos com um fim determinado". Em oposição ao conceito de razão subjetiva, Horkheimer aponta a ideia de uma razão objetiva. Na visão de Horkheimer (2002, pag. 10), "Esta concepção afirmava a existência da razão não só como uma força da mente individual, mas também do mundo objetivo: nas relações entre os seres humanos e entre as classes sociais, nas instituições sociais, e na natureza e suas manifestações".

${ }^{4}$ A Psicologia Social de Mead contribui de forma significativa para compreender outras possibilidades de relação do sujeito consigo mesmo e com os outros. Como aponta Dalbosco (2010, pag. 224), "Além disso, a contribuição de Mead na superação das aporias do modelo reflexivo da autoconsciência reside no fato de ele ter mostrado, com seu interacionismo simbólico, uma possibilidade do eu (autoconsciência) sair de si mesmo. Ou seja, ao desenvolver a capacidade de produzir e empregar símbolos significantes, o indivíduo assume o papel do outro, condição que Mead também considera indispensável para que o indivíduo possa construir a si mesmo".

${ }^{5}$ É importante observar que apesar de Mead discutir a problemática da Educação, nunca chegou de fato a elaborar ou publicar uma obra contemplando essa temática. O tema da educação encontra-se em artigos e aulas ministradas na Universidade de Chicago e anotada pelos seus alunos.

${ }^{6}$ Habermas não esboça em sua produção teórica uma análise sobre a educação ou escola propriamente dito. O que se faz, são análises da educacionais fundamentadas em seu pensamento. Como afirma Bannell (2006, p. 15), "Cabe aqui observar mais um esclarecimento: a aplicação do pensamento de Habermas para prática pedagógica na escola é um caminho cheio de armadilhas e dificuldades. Que eu saiba, o próprio Habermas nunca escreveu nada sobre a escola [...]. Os únicos textos dele sobre instituições de ensino são análises das 
funções da universidade na sociedade contemporânea [...]."

\section{Correspondência}

Jose Gilliard Santos Silva - Rua Pedro Cecílio Pereira Junior, n 135, Serrote Branco III, CEP:59300000, Caicó, Rio Grande do Norte, Brasil.

\section{(c) (1)(8)(2) \\ BY NC SA}

This work is licensed under a Creative Commons Attribution-NonCommercial 4.0 International (CC BY-NC 4.0) 